\title{
Взаємозв'язок попередніх обертань молоту у кваліфікованих метальниць молоту
}

\author{
Владислав Рожков ${ }^{1}$ \\ Віктор Павленко \\ Єлена Павленко ${ }^{2}$ \\ Тетяна Павленко \\ Тетяна Шутєєва' \\ Вячеслав Шутєєв ${ }^{4}$
}

Харківська державна академія фізичної культури ${ }^{1}$, Національний фармацевтичний університет", Харківський національний автомобільно-дорожній університет ${ }^{3}$, Харківський національний медичний університет ${ }^{4}$, Харків, Україна

Мета: дослідити взаємозв'язок першого попереднього обертання молоту із другим у кваліфікованих метальниць молоту.

Матеріал і методи: досліджувалися 8 кваліфікованих метальниць молоту, фіналісток Чемпіонату світу та кубків Європи, упродовж сезонів 2016-2019 рр. У роботі були використані наступні методи: аналіз і узагальнення науковометодичної літератури, аналіз матеріалів відеозйомки, методи математичної статистики.

Результати: у результаті кореляційного аналізу найбільш тісний взаємозв'язок було зафіксовано між часом другого попереднього обертання молоту, лінійною, кутовою швидкостями молоту, відцентрованою силою молоту, які мали спортсменки наприкінці другого попереднього обертання молоту та показниками: кут у правому, лівому ліктьових суглобах, що мали метальниці наприкінці першого попереднього обертання молоту $r=0,734-0,833$. Результати дослідження показали, що із збільшенням кутів у ліктьових суглобах впродовж першого попереднього обертання молоту, у досліджуваних спортсменок буде спостерігатися підвищення швидкісних показників молоту, відцентрованої сили молоту наприкінці другого попереднього обертання молоту, а також збільшуватися час другого попереднього обертання молоту. Такі параметри техніки першого обертання молоту як: лінійна швидкість молоту; кутова швидкість молоту; відцентрована сила молоту; тривалість першого попереднього обертання молоту - суттєвого впливу на показники техніки другого попереднього обертання молоту не мали.

Висновки: встановлено, що для ефективного виконання другого попереднього обертання молоту в технічній підготовці під час удосконалення техніки першого обертання молоту найбільше уваги слід приділяти кутам у ліктьових суглобах, траєкторії руху кулі молоту, куту у правому колінному суглобі і висоті підйому п'ятки лівої ноги над опорою наприкінці першого попереднього обертання молоту.

Ключові слова: техніка, біомеханічні параметри, попередні обертання молоту, кваліфіковані спортсменки, метання молоту.

\section{Вступ}

Попередні обертання молоту є однією з ключових фаз метання молоту, оскільки саме під час них відбувається входження у ритм метання молоту, допущення помилок унеможливлює ефективне виконання метання з молотом $[1,3]$. Дослідженням техніки попередніх обертань молоту займалися R. Isele [6], L. Judge [7], J. Silvester [10].

Аналізуючи техніку попередніх метань молоту В. О. Рожков [2], K. Bartoniet [4], встановили, що для провідних метальників сучасності характерне два попередніх обертання молоту.

Досліджуючи швидкісні показники молоту N. Fujii, Y. Koуama [5], встановили, що у процесі попередніх обертань молоту швидкість кулі молота становить 50\% від максимальної швидкості молота. За даними K. Murofushi, S. Sakurai [8], під час попередніх обертань молоту слід поступово нарощувати швидкість молоту, аби плавно увійти у перше обертання з молотом.
Згідно з результатами досліджень Shuai, W., Jihe, Z. [9] для ефективного виконання обертання з молотом, час другого попереднього обертання повинен бути 1,06 с.

Слід зазначити, що попри значні дослідження техніки метання молоту під час дослідження попередніх обертань молоту найбільше уваги приділяється швидкісним параметрам техніки, дослідженню кутових параметрів техніки попередніх обертань молоту та визначенню їх взаємозв'язку приділено і досі недостатньо уваги.

Зв'язок роботи з науковими програмами, планами, темами. Дослідження виконувалося відповідно до теми науково-дослідної роботи кафедри легкої атлетики Харківської державної академії фізичної культури: «Особливості часо-просторових характеристик спортивної (легка атлетика) та повсякденної рухової діяльності», номер держреєстрації $0119 U 103785$.

Мета дослідження: дослідити вплив техніки першого попереднього обертання молоту на біомеханічні параметри техніки другого попереднього обертання молоту. 


\section{Матеріал і методи дослідження}

Досліджувалася техніка 8 висококваліфікованих метальниць молоту, фіналісток Чемпіонату світу та кубків Європи, упродовж сезонів 2016-2019 рр. У роботі були використані наступні методи: аналіз і узагальнення науково-методичної літератури, аналіз матеріалів відеозйомки, методи математичної статистики.

\section{Результати дослідження}

Показники техніки висококваліфікованих метальниць молоту наприкінці першого попереднього обертання молоту наведені у таблиці 1.

у більшості досліджуваних параметрів техніки, коефіцієнти варіації знаходилися в проміжку $V=5,3-$
14,0\%, що свідчить про відсутність значних відмінностей у біомеханічних показниках техніки між кваліфікованими метальницями молоту.

У показниках: висота підйому п'ятки лівої ноги від опори, лінійна швидкість молоту, кутова швидкість молоту, відцентрована сила молоту спостерігалась відсутність однорідності результатів $\mathrm{V}=20,61-37,28 \%$, що пов'язано з індивідуальними особливостями техніки досліджуваних метальниць молоту.

Показники техніки висококваліфікованих метальниць молоту наприкінці другого попереднього обертання молоту наведені у таблиці 2.

Аналіз отриманих результатів виявив відсутність однорідності результатів у таких показниках техніки:

Таблиця 1

Показники техніки кваліфікованих метальниць наприкінці першого попереднього обертання молоту $(\mathrm{n}=8)$

\begin{tabular}{|c|c|c|c|}
\hline Проказник & $\bar{X}$ & $\sigma$ & $\mathrm{V} \%$ \\
\hline Кут у правому колінному суглобі $\left({ }^{\circ}\right)$ & 163,7 & 8,7 & 5,3 \\
\hline Кут у лівому колінному суглобі $\left({ }^{\circ}\right)$ & 147,8 & 12,5 & 8,4 \\
\hline Висота підйому п’ятки лівої ноги від опори (см) & 9,6 & 3,1 & 32,2 \\
\hline Кут у правому ліктьовому суглобі $\left({ }^{\circ}\right)$ & 107,5 & 8,2 & 7,6 \\
\hline Кут у лівому ліктьовому суглобі $\left(^{\circ}\right)$ & 106,9 & 8,4 & 7,8 \\
\hline Кут нахилу тулуба $\left(^{\circ}\right)$ & 11,1 & 1,6 & 14,0 \\
\hline Висота підйому кулі молоту (м) & 1,95 & 0,2 & 8,9 \\
\hline Лінійна швидкість молоту $\left(\right.$ м $\left.\cdot \mathrm{c}^{-1}\right)$ & 7,25 & 1,50 & 20,66 \\
\hline Кутова швидкість молоту (рад · $\left.{ }^{-1}\right)$. & 5,11 & 1,05 & 20,61 \\
\hline Відцентрована сила молоту (кг) & 21,0 & 7,81 & 37,28 \\
\hline Тривалість першого попереднього обертання молоту (с) & 1,06 & 0,08 & 7,36 \\
\hline
\end{tabular}

Таблиця 2

Показники техніки кваліфікованих метальниць наприкінці другого попереднього обертання молоту $(\mathrm{n}=8)$

\begin{tabular}{|c|c|c|c|}
\hline Проказник & $\overline{\bar{X}}$ & $\sigma$ & $\mathrm{V} \%$ \\
\hline Кут у правому колінному суглобі $\left(^{\circ}\right)$ & 155,6 & 9,9 & 6,4 \\
\hline Кут у лівому колінному суглобі $\left({ }^{\circ}\right)$ & 155,2 & 9,0 & 5,8 \\
\hline Висота підйому п’ятки лівої ноги від опори (см) & 9,2 & 4,5 & 48,7 \\
\hline Кут у правому ліктьовому суглобі $\left({ }^{\circ}\right)$ & 107,2 & 9,7 & 9,1 \\
\hline Кут у лівому ліктьовому суглобі $\left({ }^{\circ}\right)$ & 107,9 & 10,0 & 9,3 \\
\hline Кут нахилу тулуба $\left({ }^{\circ}\right)$ & 8,9 & 4,1 & 46,2 \\
\hline Висота підйому кулі молоту (м) & 1,99 & 0,06 & 3,2 \\
\hline Лінійна швидкість молоту $\left(\mathrm{M} \cdot \mathrm{c}^{-1}\right)$ & 9,94 & 1,42 & 14,30 \\
\hline Кутова швидкість молоту (рад · $\left.{ }^{-1}\right)$. & 6,91 & 1,01 & 14,68 \\
\hline Відцентрована сила молоту (кг) & 37,6 & 10,2 & 27,10 \\
\hline Тривалість другого попереднього обертання молоту (c) & 1,20 & 0,05 & 4,13 \\
\hline
\end{tabular}


Таблиця 3

Взаємозв'язок технік попередніх обертань молоту кваліфікованих метальниць

\begin{tabular}{|c|c|c|c|c|c|c|c|c|c|c|c|}
\hline \multirow[b]{2}{*}{$\begin{array}{l}\text { Показник } \\
\text { техніки } \\
\text { першого } \\
\text { поперед- } \\
\text { нього } \\
\text { обертання } \\
\text { молоту }\end{array}$} & \multicolumn{11}{|c|}{ Показник техніки другого попереднього обертання молоту } \\
\hline & 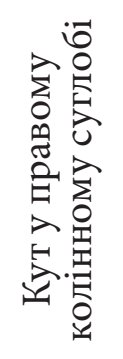 & 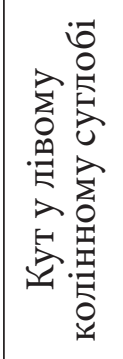 & 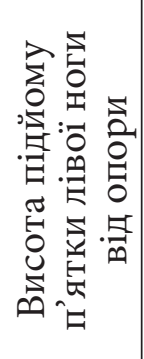 & 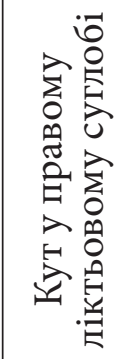 & 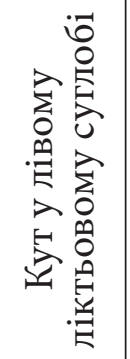 & 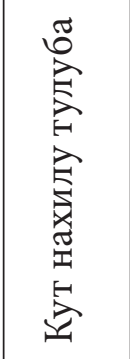 & 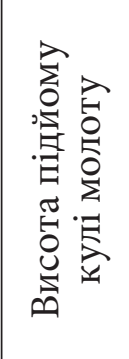 & 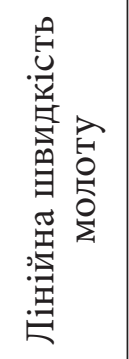 & 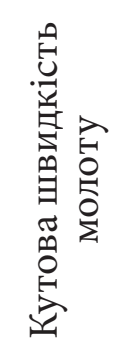 & 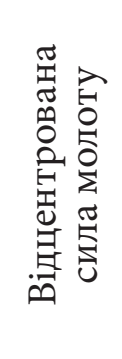 & 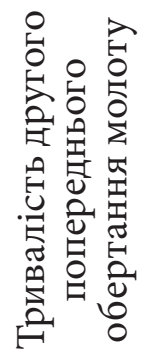 \\
\hline $\begin{array}{l}\text { Кут у } \\
\text { правому } \\
\text { колінному } \\
\text { суглобі }\end{array}$ & 0,408 & 0,513 & $-0,056$ & 0,509 & 0,528 & $-0,101$ & $-0,218$ & 0,704 & 0,636 & 0,589 & 0,100 \\
\hline $\begin{array}{l}\text { Кут у лівому } \\
\text { колінному } \\
\text { суглобі }\end{array}$ & 0,298 & 0,543 & $-0,440$ & 0,209 & 0,248 & $-0,107$ & $-0,514$ & 0,190 & 0,158 & 0,075 & $-0,208$ \\
\hline $\begin{array}{l}\text { Висота } \\
\text { підйому } \\
\text { п’ятки лівої } \\
\text { ноги від } \\
\text { опори }\end{array}$ & $-0,039$ & $-0,201$ & 0,799 & 0,316 & 0,390 & 0,084 & 0,540 & 0,362 & 0,280 & 0,329 & 0,151 \\
\hline $\begin{array}{l}\text { Кут у } \\
\text { правому } \\
\text { ліктьовому } \\
\text { суглобі }\end{array}$ & 0,059 & 0,388 & $-0,281$ & 0,707 & 0,651 & 0,434 & $-0,143$ & 0,753 & 0,830 & 0,810 & 0,833 \\
\hline $\begin{array}{l}\text { Кут у лівому } \\
\text { ліктьовому } \\
\text { суглобі }\end{array}$ & 0,072 & 0,385 & $-0,288$ & 0,679 & 0,621 & 0,454 & $-0,152$ & 0,734 & 0,816 & 0,789 & 0,825 \\
\hline $\begin{array}{l}\text { Кут нахилу } \\
\text { тулуба }\end{array}$ & $-0,201$ & $-0,207$ & 0,399 & 0,519 & 0,496 & 0,335 & 0,224 & 0,580 & 0,611 & 0,655 & 0,370 \\
\hline $\begin{array}{l}\text { Висота } \\
\text { підйому кулі } \\
\text { молоту }\end{array}$ & $-0,279$ & $-0,791$ & 0,728 & $-0,107$ & $-0,027$ & $-0,426$ & 0,770 & $-0,212$ & $-0,352$ & $-0,185$ & $-0,229$ \\
\hline $\begin{array}{l}\text { Лінійна } \\
\text { швидкість } \\
\text { молоту }\end{array}$ & 0,295 & 0,469 & 0,042 & 0,334 & 0,408 & 0,590 & $-0,517$ & 0,418 & 0,445 & 0,272 & $-0,254$ \\
\hline $\begin{array}{l}\text { Кутова } \\
\text { швидкість } \\
\text { молоту }\end{array}$ & 0,294 & 0,469 & 0,041 & 0,335 & 0,408 & 0,591 & $-0,518$ & 0,419 & 0,446 & 0,272 & $-0,253$ \\
\hline $\begin{array}{l}\text { Відцентро- } \\
\text { вана сила } \\
\text { молоту }\end{array}$ & 0,261 & 0,533 & 0,049 & 0,324 & 0,396 & 0,617 & $-0,516$ & 0,377 & 0,416 & 0,236 & $-0,205$ \\
\hline $\begin{array}{l}\text { Тривалість } \\
\text { першого } \\
\text { поперед- } \\
\text { нього } \\
\text { обертання } \\
\text { молоту }\end{array}$ & $-0,444$ & 0,507 & 0,376 & 0,156 & 0,205 & 0,249 & $-0,231$ & $-0,168$ & $-0,087$ & $-0,171$ & $-0,202$ \\
\hline
\end{tabular}


висота підйому п'ятки лівої ноги від опори, кут нахилу тулуба, відцентрована сила молоту - V= 27,10-48,7\%, що пов'язано з індивідуальними особливостями техніки та антропометричними параметрами досліджуваних спортсменок.

В інших досліджуваних показниках спостерігалась відсутність суттєвих розбіжностей між результатами у досліджуваних метальниць молоту $\mathrm{V}=3,2-14,68 \%$.

Для визначення взаємозв'язку технік попередніх обертань молоту у кваліфікованих метальниць був проведений кореляційний аналіз за методом парної кореляції Пірсона (табл. 3).

Високий ступінь взаємозв'язку було зафіксовано між часом другого попереднього обертання молоту, лінійною, кутовою швидкостями молоту, відцентрованою силою молоту, які мали спортсменки наприкінці другого попереднього обертання молоту та показниками кут у правому, лівому ліктьових суглобів, що мали метальниці наприкінці першого попереднього обертання молоту $r=0,734-0,833$.

Отримані дані свідчать, що із збільшенням кутів у ліктьових суглобах, у досліджуваних спортсменок, буде спостерігатися підвищення швидкісних показників молоту, відцентрованої сили молоту наприкінці другого попереднього обертання молоту, а також збільшуватися час другого попереднього обертання молоту.

Кореляційний взаємозв'язок свідчить про зменшення кута у лівому колінному суглобі, наприкінці другого попереднього обертання молоту, у разі збільшення висоти підйому кулі молоту наприкінці першого попереднього обертання молоту ( $r=-0,791)$.

Збільшення висоти підйому п'ятки лівої ноги від опори наприкінці другого попереднього обертання молоту буде спостерігатися у разі збільшення підйому п'ятки лівої ноги від опори, та висоти підйому кулі молоту наприкінці першого попереднього обертання молоту, про що свідчить досить високий взаємозв'язок між цими показниками $r=0,799$ та $r=0,728$ відповідно.

Досить тісний взаємозв'язок спостерігається між кутами у правих ліктьових суглобах які мають метальниці наприкінці попередніх обертань молоту $r=0,707$. Чим більше матимуть метальниці кут у правому ліктьовому суглобі наприкінці першого попереднього обертання молоту, тим у них буде більшим кут у правому ліктьовому суглобі наприкінці другого попереднього обертання молоту.
Підвищення висоти підйому кулі молоту наприкінці другого попереднього обертання молоту буде спостерігатися у разі збільшення висоти кулі молоту наприкінці першого попереднього обертання молоту $r=0,770$.

Висока ступінь взаємозв'язку була зафіксована між лінійною швидкістю молоту, яку мали метальниці наприкінці другого попереднього обертання молоту та кутом у правому колінному суглобі, який мали спортсменки наприкінці першого попереднього обертання молоту $r=704$. Коефіцієнт кореляції вказує на збільшення лінійної швидкості молоту наприкінці другого попереднього обертання у разі збільшення у спортсменок кута у правому колінному суглобі наприкінці першого попереднього обертання молоту.

\section{Висновки / Дискусія}

Результати проведеного дослідження свідчать про велике значення кутових показників техніки першого попереднього обертання молоту для ефективного виконання його другого попереднього обертання. Отримані дані підтверджують відомості J. Silvester [10], K. Bartonietz [4], щодо збільшення висоти кулі молоту у другому попередньому обертання у разі руху молоту по більш високій траєкторії впродовж його першого попереднього обертання. Досліджуючи швидкісні параметри техніки K. Murofushi [8], N. Fujii [5], встановили приріст лінійної швидкості молоту до 50 \% у другому попередньому обертання молоту у порівнянні з першим, у той же час отримані нами дані не виявили значної залежності між швидкісними параметрами техніки попередніх обертань молоту $r=0,418-0,486$.

Отримані дані розширили відомості W. Shuai [9], щодо впливу на часові параметри техніки попередніх обертань молоту, виявлено що чим більшими будуть кути у ліктьових суглобах впродовж першого попереднього обертання молоту, тим довше триватиме друге попереднє обертання молоту $r=0,789-0,810$.

Встановлено, що для ефективного виконання другого попереднього обертання молоту, слід у технічній підготовці під час удосконалення техніки першого обертання молоту найбільше уваги приділяти кутам у ліктьових суглобах, траєкторії руху кулі молоту, куту у правому колінному суглобі і висоті підйому п'ятки лівої ноги над опорою наприкінці першого попереднього обертання молоту.

Перспективи подальших досліджень. Передбачається встановити взаємозв'язок між попередніми обертаннями молоту та обертаннями з молотом.

Конфлікт інтересів. Автори заявляють, що немає конфлікту інтересів, який може сприйматися як такий, що може завдати шкоди неупередженості статті.

Джерела фінансування. Ця стаття не отримала фінансової підтримки від державної, громадської або комерційної організації.

\section{Список посилань}

1. Рожков В. О. (2020), «Взаємозв'язок техніки другого попереднього обертання молоту з технікоюпершого обертання з молотом у кваліфікованих метальниць», Науковий часопис НПУ ім. Драгоманова. Серія 15: Науково-педагогічні проблеми фізичної культури (фізична культура і спорт), № 2 (112), С. 144-148.

2. Рожков В. О. (2018), «Особливості виконання попередніх обертань молоту кваліфікованими метальниками», Науковий часопис НПУ ім. Драгоманова. Серія 15: Науково-педагогічні проблеми фізичної культури (фізична культура і спорт), № 10 (104), C. $75-81$.

3. Рожков В. О. (2019), «Вплив техніки замаху молоту на техніку його першого попереднього обертання у кваліфікованих метальників», Науковий часопис НПУ ім. Драгоманова. Серія 15: Науково-педагогічні проблеми фізичної культури (фізична культура і спорт), № 3 (111), С. 156-163. 
4. Bartonietz K. (2000), Hammer throwing: problems and prospects, Blackwell Science, United Kingdom, pp. 459-486.

5. Fujii N., Koyama, Y. (2007), «Reexamination of acceleration mechanism in hammer throw», Journal of Biomechanics, № 40 (2), pp. 622.

6. Isele R., Nixdorf, E. (2010), «Biomechanical analysis of the hammer throw at the 2009 IAAFWorld Championships in Athletics», New studies in athletics, № 25, pp. 37-60.

7. Judge L. (2000), «The hammer throw for men \& women», Coach and athletic director, № 69 (7), pp. 36-41.

8. Murofushi K., Sakurai S., Umegaki K. (2007), «Hammer acceleration due to the thrower and hammer movement patterns», Sports biomechanics, № 6 (3), pp. 301-314.

9. Shuai W., Jihe Z., Chong J. (2014), «Kinematics Analysis on the Throwing Skills of Elite Chinese Male Hammer Athletes», Japan Journal of Physical Education, Health and Sport Sciences, № 950 (4), pp. 91-92.

10. Silvester J. (2003), Complete book of throws, Human Kinetics, South Australia, pp. 131-155.

Стаття надійшла до редакції: 13.01.2021 р.

Опубліковано: 22.02.2021 p.

\begin{abstract}
Аннотация. Владислав Рожков, Виктор Павленко, Елена Павленко, Татьяна Павленко, Татьяна Шутеева, Вячеслав Шутеев. Взаимосвязь техник предварительных вращений молота у квалифицированных метательниц молота. Цель: исследовать взаимосвязь первого предварительного вращения молота со вторым, у квалифицированных метательниц молота. Материал и методы: исследовались 8 квалифицированных метательниц молота, финалистки Чемпионата мира и кубков Европы в течении сезонов 2016-2019 рр. В работе были использованы следующие методы: анализ и обобщение научно-методической литературы, анализ материалов видеосъёмки, методы математической статистики. Результаты: в результате корреляционного анализа наиболее тесную взаимосвязь было зафиксировано между временем второго предварительного вращения молота; линейной, угловой скоростями молота; центробежной силой молота, которую имели спортсменки в конце второго предварительного вращения молота и показателями: угол в правом, левом локтевых суставах, которые имели метательницы в конце первого предварительного вращения молота $r=0,734-0,833$. Результаты исследования показали, что с увеличением углов в локтевых суставах, во время первого предварительного вращения молота у исследуемых спортсменок, будет наблюдаться увеличение скоростных показателей молота, центробежной силы молота в конце второго предварительного вращения молота, а так же увеличение времени второго предварительного вращения молота. Такие параметры техники первого предварительного вращения молота как: линейная скорость молота, угловая скорость молота, центробежная сила молота, время первого вращения молота - существенного влияния на показатели техники второго предварительного вращения молота не имели. Выводы: установлено, что для эффективного выполнения второго предварительного вращения молота, следует в технической подготовке, во время совершенствования техники первого предварительного вращения молота, наибольшее внимание уделять углам в локтевых суставах, траектории движения шара молота, углу в правом коленном суставе и высоте подьема пятки левой ноги над опорой в конце первого предварительного вращения молота.
\end{abstract}

Ключевые слова: техника, биомеханические параметры, предварительные вращения молота, квалифицированные спортсменки, метание молота.

Abstract. Vladyslav Rozhkov, Viktor Pavlenko, Yelena Pavlenko, Tatyana Pavlenko, Tetiana Shutieieva, Viacheslav Shutieiev. Relationship between biomechanical parameters techniques of the preliminary rotation among elite women hammers throwers. Purpose: to determine the relationships technique of the first preliminary rotation with technique of the second preliminary swing elite women hummer throwers. Material and Methods: the research was attended by 8 hammer throwers (women) finalists' of European championships, and World championship during the 2016-2019 seasons. Research methods used: analysis and generalization of literary sources, processing video materials, methods of mathematical statistics. Results: very strong correlation was observed between times of the second preliminary rotation linear, angular velocities of the hammer, centrifugal force of the hammer at the end of the second preliminary rotation and angles in the right and left elbows at the end of the first preliminary rotation $r=0,734-$ 0,833. The correlation coefficient showed that if research women hummer throwers have more angles in the right and left elbows at the end of the first preliminary rotation they will have more time of the second preliminary rotation, linear, angular velocities of the hammer, centrifugal force of the hammer at the end of the second preliminary rotation. As a result correlations analysis was discovered that such parameters of technique first pre- rotation as: linear velocity of the hammer, angular velocity of the hammer, centrifugal force of the hammer, time of the first preliminary rotation don't have significant impact on the technique second pre-swing. Conclusions: the findings suggest established that for effective implementation second preliminary rotation during improvement technique of the first preliminary rotation the most attention should devote angles in the elbow joints, trajectory of the hammer, angle in the right knee and height lifting of the left heel from support at the end of the first preliminary rotation.

Keywords: technique, biomechanical parameters, preliminary rotations, elite women athletes, hammer throw.

\title{
References
}

1. Rozhkov, V. (2020), «Relationship between biomechanical parameters technique of the second preliminary swings and biomechanical parameters technique of the first turn among elite woman hammer throwers», Naukovyi chasopys Natsionalnoho pedahohichnoho universytetu imeni M. P. Drahomanova. Seriia 15 : Naukovo-pedahohichni problemy fizychnoi kultury (fizychna kultura i sport), No. 2 (112), pp. 144-148. (in Ukr.).

2. Rozhkov, V. (2018), «Peculiarities of execution previous rotations hammer of qualified throwers", Naukovyi chasopys Natsionalnoho pedahohichnoho universytetu imeni M. P. Drahomanova. Seriia 15: Naukovo-pedahohichni problemy fizychnoi kultury (fizychna kultura i sport), No. 10 (104), pp. 75-81. (in Ukr.).

3. Rozhkov, V. (2019), «Relationship of technique of the backswing hammer with his first previous rotation at the qualified throwers", Naukovyi chasopys Natsionalnoho pedahohichnoho universytetu imeni M. P. Drahomanova. Seriia 15 : Naukovo-pedahohichni problemy fizychnoi kultury (fizychna kultura i sport), No. 3 (111), pp. 156-163. (in Ukr.). 
4. Bartonietz, K. (2000), Hammer throwing: problems and prospects, Blackwell Science, United Kingdom, pp. 459-486. (in Eng.).

5. Fujii, N., Koyama, Y. (2007), «Reexamination of acceleration mechanism in hammer throw», Journal of Biomechanics, No. 40 (2), pp. 622. (in Eng.).

6. Isele, R., Nixdorf, E. (2010), «Biomechanical analysis of the hammer throw at the 2009 IAAFWorld Championships in Athletics», New studies in athletics, No. 25, pp. 37-60. (in Eng.).

7. Judge, L. (2000), «The hammer throw for men \& women», Coach and athletic director, No. 69 (7), pp. 36-41. (in Eng.).

8. Murofushi, K., Sakurai, S., Umegaki, K. (2007), «Hammer acceleration due to the thrower and hammer movement patterns», Sports biomechanics, No. 6 (3), pp. 301-314. (in Eng.).

9. Shuai, W., Jihe, Z., Chong, J. (2014), «Kinematics Analysis on the Throwing Skills of Elite Chinese Male Hammer Athletes», Japan Journal of Physical Education, Health and Sport Sciences, No. 950 (4), pp. 91-92. (in Eng.).

10. Silvester, J. (2003), Complete book of throws, Human Kinetics, South Australia, pp. 131-155. (in Eng.).

Received: 13.01.2021.

Published: 22.02.2021.

\section{Відомості про авторів / Information about the Authors}

Рожков Владислав Олександрович: к.фіз.вих., Харківська державна академія фізичної культури: вул. Клочківська 99, м. Харків, 61058, Україна.

Рожков Владислав Александрович: к.физ.восп., Харьковская государственная академия физической культуры: ул. Клочковская 99, г. Харьков, 61058, Украина.

Vladyslav Rozhkov: PhD (Physical Education and Sport), Kharkiv State Academy of Physical Culture: Klochkivska str. 99, Kharkiv, 61058, Ukraine

ORCID.ORG/0000-0002-5110-6046

E -mail: vladyslav.oleksandrovych@gmail.com

Павленко Віктор Олексійович: к.пед.наук, доцент; Харківська державна академія фізичної культури: вул. Клочківська 99, м. Харків, 61058, Україна.

Павленко Виктор Алексеевич: к.пед. наук, доцент; Харьковская государственная академия физической культуры: ул. Клочковская 99, г. Харьков, 61058, Украина.

Viktor Pavlenko: Cand. of Ped. Sciences, Associate Professor; Kharkiv State Academy of Physical Culture: Klochkivska str. 99, Kharkiv, 61058, Ukraine.

ORCID.ORG/0000-0003-0888-2485

E-mail: pavlenko102@ukr.net

Павленко Єлена Євгеніївна: Національний фармацевтичний університет: вул. Пушкінська 53, м. Харків, 61000, Україна. Павленко Елена Евгениевна: Национальный фармацевтический университет: ул. Пушкинская 53, г. Харьков, 61000, Украина.

Yelena Pavlenko: National Pharmaceutical University: 53 Pushkinskayastr., Kharkiv, 61000, Ukraine.

ORCID.ORG/0000-0001-7204-1475

E-mail: elenapavlenko102@gmail.com

Павленко Тетяна Вікторівна: к.пед.наук, Харківський національний автомобільно-дорожній університет, вул. Ярослава Мудрого 25, м. Харків, 61000, Україна.

Павленко Татьяна Викторовна: к.пед.наук, Харьковский национальный автомобильно-дорожный университет, ул. Ярослава Мудрого 25, г. Харьков, 61000, Украина.

Tatyana Pavlenko: Cand. of Ped. Sciences, Kharkiv National Automobile and Highway University, Yaroslava Mudrogo str. 25, Kharkiv, Ukraine.

ORCID.ORG/0000-0003-3517-5735

E-mail: pavlenkotv102@gmail.com

Шутєєва Тетяна Миколаївна: Харківська державна академія фізичної культури: вул. Клочківська 99, м. Харків, 61058, україна.

Шутеева Татьяна Николаевна: Харьковская государственная академия физической культуры: ул. Клочковская 99, г. Харьков, 61058, Украина.

Tetiana Shutieieva: Kharkiv State Academy of Physical Culture: Klochkivska str. 99, Kharkiv, 61058, Ukraine.

ORCID.ORG/0000-0001-6459-8564

E-mail: stn150371@gmail.com

Шутєєв Вячеслав Вадимович: к.фіз.вих., доцент; Харківський національний медичний університет: просп. Науки 4, м. Харків, 61022, Україна.

Шутеев Вячеслав Вадимович: к.физ.восп., доцент; Харьковский национальный медицинский университет: ул. Науки 4, г. Харьков, 61022, Украина.

Viacheslav Shutieiev: PhD (Physical Education and Sport), Associate Professor; Kharkiv national medical university: avenue Science 4, Kharkiv, 61022, Ukraine.

ORCID.ORG/0000-0001-6459-8564

E-mail: shutey1971@ukr.net 